\title{
Editorial
}

\section{Editorial: $\operatorname{CORR}^{\mathbb{R}}$ Thanks its Peer Reviewers}

\author{
Seth S. Leopold MD
}

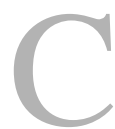

linicians don't turn to journals for data. Rather, we look for knowledge, for answers to our most-pressing questions. Surgeons are awash in oceans of data, and background noise comes free online.

Apart from a growing number of brand-name journals-Thomson Reuters indexed more than 70 orthopaedic titles last year [4]—we find countless

The author certifies that he, or any members of his immediate family, has no commercial associations (eg, consultancies, stock ownership, equity interest, patent/licensing arrangements, etc) that might pose a conflict of interest in connection with the submitted article.

All ICMJE Conflict of Interest Forms for authors and Clinical Orthopaedics and Related Research ${ }^{\mathbb{R}}$ editors and board members are on file with the publication and can be viewed on request.

The opinions expressed are those of the writers, and do not reflect the opinion or policy of $\operatorname{CORR}^{\mathbb{R}}$ or the Association of Bone and Joint Surgeons ${ }^{\circledR}$.

S. S. Leopold MD ( $\square)$

Clinical Orthopaedics and Related

Research®, 1600 Spruce St.,

Philadelphia, PA 19103, USA

e-mail: sleopold@clinorthop.org sources of varying quality, some of which are dubious and still others frankly predatory. And the latter appear to be gaining ground. One watchdog suggests that the number of predatory open-access publishers, defined as those that charge publication fees but do not provide the basic editorial and publishing services one might associate with legitimate journals, has increased more than $5000 \%$ over the last 6 years (from 18 to 923). Additionally, the number of predatory standalone open-access journals has increased sevenfold over the last 4 years [1]. The ecosystem of predatory journals may now exceed 8000 [3].

All of these sources contain content. They do not all contain high-quality evidence. Readers depend on the best sources of knowledge to separate signal from noise.

Clinical Orthopaedics and Related Research ${ }^{\circledR}$ does this at several levels, but none is more important than external review. By sharing their subject-matter expertise with us, CORR's peer reviewers help editors to separate the useful from the been-there-donethat (and from the frankly misleading). By offering their perspectives to authors, our reviewers help scientists who publish here to refine and clarify their messages.
This year, $C O R R^{\circledR}$ hit new highs in every important metric: 2- and 5-year Impact Factors, full-text downloads, and the number of individuals who have access to the knowledge we disseminate. CORR's success is tied to its quality, and its quality derives in large measure from its expert reviewer pool.

Although reviewing is a volunteer task, it is not a thankless one. Reviewers have the gratitude of every author whose work they improved. The editorial board of $C O R R^{\circledR}$ knows and appreciates that reviewers make our mission possible; recognizing this, we have tried to make a hard job easier and more efficient by providing our reviewers with a novel tool, which is freely available at http://www.clinorthop.org/reviewertool [2]. And while patients may not know precisely how discoveries are made or disseminated, there is no question they appreciate that the work was done, and done well.

Since this time last year, more than 1300 reviewers participated in CORR's peer-review process. I am grateful to every single one. In particular, I would like to recognize our "Top Reviewers," who completed four or more reviews between September 2015 and August 2016, and who earned an average review score in the 
"excellent" range during that time. Fewer than $5 \%$ of those who reviewed last year made this list. I thank all our reviewers for their time and expertise, and I congratulate CORR's "Top Reviewers" for their special accomplishment in an acknowledgement at the end of this issue (DOI: 10.1007/ s11999-016-5101-z).

\section{References}

1. Beall's list of predatory publishers 2016. https://scholarlyoa.com/2016/01/ 05/bealls-list-of-predatory-publishers-

2016/. Accessed on September 1, 2016.

2. Leopold SS. Editorial: CORR's new peerreviewer tool-Useful for more than peer reviews. Clin Orthop Relat Res. [Published online ahead of print August 30, 2016]. DOI: 10.1007/s11999-016-5050-6.
3. Shen C, Björk B-C. Predatory open access: A longitudinal study of article volumes and market characteristics. BMC Medicine. 2015;13:230.

4. Thomson Reuters. Science citation index expanded - orthopedics-journal list. http://science.thomsonreuters.com/ cgi-bin/jrnlst/jlresults.cgi?PC=D\&SC= TC. Accessed on September 1, 2016. 